\title{
Prevalence, awareness, treatment, and control of hypertension in Northern China: a cross-sectional study
}

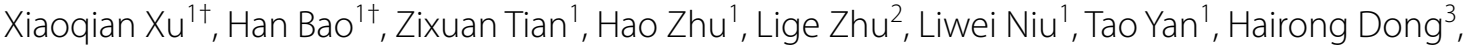 \\ Xin Fang ${ }^{1 *}$ and Xingguang Zhang ${ }^{1,2^{*}}$ (D)
}

\begin{abstract}
Background: Hypertension has always been a worldwide health concern. The purpose of this study was to investigate the prevalence, awareness, treatment, and control rates of hypertension among adult residents of northern China, where people usually have a high-fat, high-salt diet and heavy alcohol consumption.

Methods: Through the Early Screening and Comprehensive Intervention Project for High Risk Groups of Cardiovascular Diseases in the Inner Mongolia of northern China, we collected data of 70,380 residents, from September 2015 to June 2017. We assessed the prevalence, awareness, treatment, and control of hypertension in the total population and sub-populations. Multivariable logistic regression analyses were used to identify the factors associated with the prevalence and control of hypertension.

Results: Among participants, only 13.4\% had optimal blood pressure levels. About 55.7\% (95\% confidence interval $(\mathrm{Cl})=55.3-56.1 \%)$ of the participants had hypertension. In addition, the awareness, treatment, control and control under-treatment rate of hypertension were $52.8 \%(95 \% \mathrm{Cl}=52.3-53.3 \%), 43.3 \%(95 \% \mathrm{Cl}=42.8-43.8 \%), 8.6 \%$ $(95 \% \mathrm{Cl}=8.3-8.9 \%)$ and $19.8 \%(95 \% \mathrm{Cl}=19.2-20.4 \%)$, respectively. Multivariable logistic regression showed that older, male, Han, living in rural areas, current drinker, not married, lower educational level, lower annual income, diabetes, obesity, and dyslipidemia were more likely to be suffered from hypertension $(P<0.05)$. Controlled hypertension was less common in those younger, Mongol, not married, farmer, current drinker, lower educational level, obesity, diabetes, without prior CHD, and without prior CVD $(P<0.05)$.
\end{abstract}

Conclusion: Among populations aged 35-75 years in Northern China, more than half have hypertension, fewer than one-tenth have successfully controlled hypertension, and fewer than one-fifth of hypertension patients receiving treatment have controlled hypertension.

Keywords: Hypertension epidemiology, Blood pressure, China, Prevalence, Control, Associated factors

*Correspondence: 532406217@qq.com; zxg311@126.com ${ }^{\dagger}$ Xiaoqian Xu and Han Bao contributed equally to this study

${ }^{1}$ School of Public Health, Inner Mongolia Medical University, Hohhot, Inner Mongolia, People's Republic of China

Full list of author information is available at the end of the article

\section{Background}

Hypertension is a leading health risk [1, 2]. Hypertension contributes to $51 \%$ of stroke deaths and $45 \%$ of ischemic heart disease deaths worldwide [3] and causes more than 7 million premature deaths each year [4]. The Global Burden of Disease Study 2019 indicated that high systolic blood pressure (SBP) accounted for 10.8 million deaths and was responsible for the largest number of all-cause 
deaths [5]. Studies have shown that the global prevalence of hypertension has risen continuously in recent decades, especially in low-income and middle-income countries [2]. It is estimated that $26.4 \%$ (972 million) of adults had hypertension in 2000, and the number in 2025 is predicted to increase by about $60 \%$, to a total of 1.56 billion globally [3]. The number of Chinese adult patients with hypertension increased from 153 million in 2000 to more than 270 million in 2012 [4]. A national study during 2014-2017 showed that 44.7\% of Chinese adults aged 35-75 years had hypertension [6]. However, the level of hypertension management remains suboptimal in China, with fewer than half of patients with hypertension in China receiving treatment and fewer than one-fifth with controlled [7, 8].

Studies have shown that the prevalence of hypertension in southern China is lower than that in the northern part of the country [7]. Because Inner Mongolia lies across a large part of northern China, it is somewhat representative of this region, where people have a high-fat, high-salt diet and heavy alcohol consumption [9]. However, previous studies have covered a limited area and have included small sample size, and most studies have not linked hypertension with demographic characteristics and clinical variables of sub-populations [10-13]. The disease burden of hypertension in northern China remains unclear and identifying adverse factors involved in hypertension is urgent. Thus, obtaining reliable information about the prevalence, awareness, treatment, and control of hypertension is critical for further prevention and control of this disease and diseases secondary to hypertension.

Accordingly, in this study, we aimed to provide updated and reliable data on the hypertension prevalence, awareness, treatment, and control of the total population and sub-populations in northern China's Inner Mongolia, and to identify the factors associated with the prevalence and control of hypertension.

\section{Materials and methods Study population}

The study comes from the Early Screening and Comprehensive Intervention Project for High-Risk Groups of Cardiovascular Diseases in Inner Mongolia. Multistage cluster sampling method was used to recruit the study population, from September 2015 to June 2017. In the first stage, we selected 6 sites (Hohhot, Wuhai, Chifeng, Erdos, Hulun Buir, and Xingan League) from Inner Mongolia, according to the economic level, geographical location, and distribution of ethnic minority nationalities, etc. In the second stage, the local Centre for Disease Control and Prevention then identified one district or county at each site based on the urban-rural distribution and population stability. In the third stage, we selected two or three urban residential communities or rural villages from each of the districts or counties according to the size of the communities or villages. In the final stage, invite the residents from each of the communities or villages to participate in the study through extensive publicity on television, broadcast and in the newspaper. The study population comprised 70,380 participants who were aged 35-75 years and lived there for at least 6 of the previous 12 months. This project was approved by the ethics committee of Fuwai Hospital Chinese Academy of Medical Sciences (approval number: 2014-574, approval date: July 2014), and all participants gave their written informed consent.

\section{Measurement}

We used a self-designed questionnaire and trained medical personnel conducted face-to-face interviews. The questionnaire mainly included demographic characteristics such as age, ethnic group, education, marital status, annual Income, health insurance, history of the disease, and lifestyle factors including smoking and drinking. Information on height, weight, blood pressure, fasting blood lipids, and fasting blood glucose was obtained in physical or laboratory examinations.

For each participant, we measured blood pressure by electronic blood pressure monitor (Omron HEM-7430; Ormon Corporation, Kyoto, Japan) two times on the right upper arm after at least $5 \mathrm{~min}$ of rest in a seated position. If the SBP or DBP difference is $>5 \mathrm{mmHg}$, the third time is measured, and the average blood pressure value of the two or three readings was used. We measured the height and weight of participants by calibrated height and weight instrument. Before the measurement, the subject removed the shoes and hats, took out the weight in the pocket, stood upright when standing, straightened the back, and naturally sagged. The eyes are looking straight ahead and the values are recorded after the values are stable. After at least $10 \mathrm{~h}$ of overnight fasting, venous blood samples were collected for the measurement of blood glucose and blood lipids. Blood glucose was measured by a glucose analyzer (BeneCheck PD-G001-2, Taiwan, China). A blood lipid test that measured triglyceride (TG), total cholesterol (TC), high-density lipoprotein cholesterol (HDL-C), and low-density lipoprotein cholesterol (LDL-C) was performed by a rapid lipid analyzer (CardioChek PA Analyzer; Polymer Technology Systems, Indianapolis, Indiana, USA).

\section{Definition}

Hypertension referred to an average $\mathrm{SBP} \geq 140 \mathrm{mmHg}$ and/or average diastolic blood pressure $(\mathrm{DBP}) \geq 90 \mathrm{mmHg}$, or self-reported use of antihypertensive medications in the past 2 weeks. Awareness 
referred to a self-reported hypertension history or selfreported use of antihypertensive drugs among patients with hypertension. Treatment of hypertension referred to the use of antihypertensive medication among participants with hypertension. Control of hypertension referred to an average $\mathrm{SBP}<140 \mathrm{mmHg}$ and an average $\mathrm{DBP}<90 \mathrm{mmHg}$ among patients with hypertension. Control under treatment referred to an average $\mathrm{SBP}<140 \mathrm{mmHg}$ and average $\mathrm{DBP}<90 \mathrm{mmHg}$ after using antihypertensive medication among patients with hypertension. According to the 2018 Revision of Chinese Guidelines for Hypertension Prevention and Control [14], optimal blood pressure is defined as an average SBP 90-119 mmHg and DBP 60-79 mmHg. High-normal, stage 1 , stage 2 , and stage 3 are defined as average SBP 120-139 $\mathrm{mmHg}$ and/or DBP $80-89 \mathrm{mmHg}$, SBP 140-159 $\mathrm{mmHg}$ and/or DBP 90-99 $\mathrm{mmHg}$, SBP 160-179 $\mathrm{mmHg}$ and/or DBP 100-109 $\mathrm{mmHg}$, and $\mathrm{SBP} \geq 180 \mathrm{mmHg}$ and/or $\mathrm{DBP} \geq 110 \mathrm{mmHg}$, respectively. If SBP and DBP had different grades, the higher grade was chosen.

Body mass index (BMI) referred to weight in kilograms $(\mathrm{kg})$ divided by height in meters squared $\left(\mathrm{m}^{2}\right)$. Obesity [15] referred to a BMI of at least $28 \mathrm{~kg} /$ $\mathrm{m}^{2}$. Diabetes [16] referred to the use of hypoglycemic medication or a measured fasting blood glucose level $\geq 7.0 \mathrm{mmol} / \mathrm{L}$ or non-fasting blood glucose level $\geq 11.1 \mathrm{mmol} / \mathrm{L}$. Dyslipidemia [17] referred to either $\mathrm{TG} \geq 2.26 \mathrm{mmol} / \mathrm{L}, \quad \mathrm{TC} \geq 6.22 \mathrm{mmol} / \mathrm{L}$, $\mathrm{LDL}-\mathrm{C} \geq 4.14 \mathrm{mmol} / \mathrm{L}, \mathrm{HDL}-\mathrm{C}<1.04 \mathrm{mmol} / \mathrm{L}$, or selfreported use of lipid-lowering drugs. Current drinker referred to drinking alcohol at least 1 time/month in the previous 1 year. Current smoker referred to smoking at least 1 cigarette every day.

\section{Statistical analysis}

Statistical analyses were performed using SAS version 9.4 (SAS Institute, Cary, NC, USA). Based on data of the sixth national census of China 2010 (National Bureau of Statistics), the age- and sex-standardized rates of hypertension prevalence at the national level were calculated by the direct method. Continuous variables were expressed as mean and standard deviations (SD) and compared using the analysis of $t$-test, $t^{\prime}$ test, or Wilcoxon rank sum test. Categorical variables were reported as numbers and proportions. Proportions were compared using the Pearson Chi-square test or Trend Chi-square tests. To analyze the association between individual characteristics and prevalence as well as control of hypertension, multivariable logistic regression models was built using hypertension prevalence and control as dependent variable $(\mathrm{No}=0$, Yes $=1)$. Independent variables with $P$ value $\leq 0.10$ in the univariable analysis were then included in the multivariable logistic regression model, performing in stepwise manner in the final multivariable logistic regression model via the Forward: LR method. Estimating adjusted odds ratios (ORs) and 95\% CI using multivariable logistic regression. The independent variables and their coding are shown in Table 1. A two-sided $P$ value $<0.05$ was considered statistically significant.

Table 1 Independent variables and their coding

\begin{tabular}{ll}
\hline Variable & Categories \\
\hline Sex & Male $=1$ (reference), female $=2$ \\
Location of residence & Rural $=1$ (reference), urban $=2$ \\
Marital status & Not married $=1$ (reference), married $=2$ \\
Farmer & No $=1$ (reference), yes $=2$ \\
Health insurance & No $=1$ (reference), yes $=2$ \\
Diabetes & No $=1$ (reference), yes $=2$ \\
Obesity & No $=1$ (reference), yes $=2$ \\
Dyslipidemia & No $=1$ (reference), yes $=2$ \\
Current smoker & No $=1$ (reference), yes $=2$ \\
Current Drinker & No $=1$ (reference), yes $=2$ \\
Prior CVD & No $=1$ (reference), yes $=2$ \\
Prior CHD & No $=1$ (reference), yes $=2$ \\
Ethnicity & Han $=1$ (reference), Mongol $=2$, others $=3$ \\
Age (years) & $35-44=1$ (reference), 45-54 $=2,55-64=3,65-75=4$ \\
Annual household income (yuan) & Low $(<10,000)=1$ (reference), middle $(10,000-50,000)=2$, high $(>50,000)=3$ \\
Educational level & Low (primary school or lower) $=1$ (reference), middle (middle school) $=2$, \\
& high (high school) $=3$ \\
\hline
\end{tabular}




\section{Results}

A total of 70,380 participants aged $35-75$ years were included in the study. Among participants, $58.0 \%$ were female, the mean age were 54.4 (SD: 9.4) years. The mean SBP and DBP was 140.5 (SD: 20.9) $\mathrm{mmHg}$ and 84.8 (SD: 11.6) $\mathrm{mmHg}$, respectively. The prevalence of diabetes was $19.5 \%$ and the mean BMI was 25.8 (SD: 3.6$) \mathrm{kg} / \mathrm{m}^{2}$ (Table 2).

\section{Mean blood pressure levels and distribution of blood pressure}

Figure 1 shows sex- and age-specific mean blood pressure values for all participants and for 3 subgroups defined by hypertension status. The mean blood pressure in our study was $140.5 / 84.4 \mathrm{mmHg}$ (male $140.7 / 86.7 \mathrm{mmHg}$ and female $140.4 / 83.4 \mathrm{mmHg}$ ). Overall, the mean SBP increased gradually with age throughout the entire age range, whereas the mean DBP decreased in the 65-75 age group. Overall, the mean SBP and DBP among participants with no hypertension were $31.0(95 \% \mathrm{CI}=30.6-$ $31.3) \mathrm{mmHg}$ and $13.6(95 \% \mathrm{CI}=13.4-13.8) \mathrm{mmHg}$ lower than the corresponding values among those with treated hypertension, and $38.3(95 \% \mathrm{CI}=37.8-38.9) \mathrm{mmHg}$ and $18.3(95 \% \mathrm{CI}=17.9-18.6) \mathrm{mmHg}$ lower than the corresponding values for those with untreated hypertension. The overall SBP and DBP differences between treated and untreated participants with hypertension were 7.4 $(95 \% \mathrm{CI}=6.8-8.0) \mathrm{mmHg}\left(t^{\prime}=-20.644, P<0.001\right)$ and $4.6(95 \% \mathrm{CI}=4.2-5.0) \mathrm{mmHg}\left(t^{\prime}=-22.999, P<0.001\right)$, respectively.

Figure 2 shows the percentage distribution of blood pressure levels among study participants. Overall, only $13.4 \%$ of the study population (11.5\% of male and $14.7 \%$ of female) had optimal blood pressure, whereas nearly two-fifths (38.8\%) had high normal blood pressure. The prevalence of stage 1, 2, and 3 hypertension was $30.7 \%$, $10.7 \%$, and $6.3 \%$ in male and $29.4 \%, 12.3 \%$, and $6.2 \%$ in female, respectively. With increasing age, the percentage of optimal and high normal blood pressure decreased whereas the proportion of stage 1 , stage 2 , and stage 3 hypertension increased (Trend Chi-square tests: male, $x^{2}=999.904, P<0.001$; female, $\left.x^{2}=41,666.177, P<0.001\right)$.

\section{Prevalence, awareness, treatment, and control of hypertension}

Table 3 shows the prevalence, awareness, treatment, control and control under treatment of hypertension by sub-populations. The crude rates of prevalence awareness, treatment, control and control under treatment for hypertension was $55.7 \%(95 \% \mathrm{CI}=55.3-56.1 \%), 52.8 \%$ $(95 \% \mathrm{CI}=52.3-53.3 \%), 43.3 \%(95 \% \mathrm{CI}=42.8-43.8 \%), 8.6 \%$ $(95 \% \mathrm{CI}=8.3-8.9 \%)$ and $19.8 \% \quad(95 \% \mathrm{CI}=19.2-20.4 \%)$,
Table 2 Baseline characteristics of the study population

\begin{tabular}{|c|c|}
\hline Characteristics & $\begin{array}{l}\text { All subjects } \\
(N=70,380)\end{array}$ \\
\hline Age (years), mean $\pm S D$ & $54.4 \pm 9.4$ \\
\hline \multicolumn{2}{|c|}{ Blood pressure $(\mathrm{mmHg})$, mean $\pm S D$} \\
\hline $\mathrm{SBP}$ & $140.5 \pm 20.9$ \\
\hline $\mathrm{DBP}$ & $84.8 \pm 11.6$ \\
\hline $\mathrm{BMI}\left(\mathrm{kg} / \mathrm{m}^{2}\right)$, mean $\pm \mathrm{SD}$ & $25.8 \pm 3.6$ \\
\hline \multicolumn{2}{|l|}{ Sex, n (\%) } \\
\hline Male & $29,539(42.0)$ \\
\hline Female & $40,841(58.0)$ \\
\hline \multicolumn{2}{|l|}{ Location of residence, n (\%) } \\
\hline Rural & $48,695(69.2)$ \\
\hline Urban & $21,685(30.8)$ \\
\hline \multicolumn{2}{|l|}{ Marital status } \\
\hline Married & $64,203(91.2)$ \\
\hline Not married & $6177(8.8)$ \\
\hline \multicolumn{2}{|l|}{ Ethnicity, n (\%) } \\
\hline Han & $63,172(89.8)$ \\
\hline Mongolian & $6086(8.6)$ \\
\hline Others & $1122(1.6)$ \\
\hline \multicolumn{2}{|c|}{ Annual household income, n (\%) } \\
\hline$<10,000$ (yuan) & $19,716(28.0)$ \\
\hline 10,000-50,000 (yuan) & $36,980(52.6)$ \\
\hline$>50,000$ (yuan) & $8044(11.4)$ \\
\hline Unknown & $5640(8.0)$ \\
\hline \multicolumn{2}{|l|}{ Educational level, n (\%) } \\
\hline Primary school or lower & $28,466(40.5)$ \\
\hline Middle school & $30,576(43.4)$ \\
\hline High school or above & $7814(11.1)$ \\
\hline Unknown & $3524(5.0)$ \\
\hline Farmer, n (\%) & $33,186(47.2)$ \\
\hline Health insurance, n (\%) & $61,139(86.9)$ \\
\hline Diabetes, n (\%) & $13,707(19.5)$ \\
\hline Dyslipidemia, n (\%) & $27,220(38.7)$ \\
\hline Obesity, n (\%) & $17,498(24.9)$ \\
\hline Current smoker, n (\%) & $17,624(25.0)$ \\
\hline Current drinker, n (\%) & $19,089(27.1)$ \\
\hline
\end{tabular}

Data are reported as $n(\%)$ or mean $\pm S D$. SD Standard deviation, SBP systolic blood pressure, $D B P$ diastolic blood pressure, $B M I$ body mass index

respectively. The national standardized prevalence rate was $49.4 \%(95 \% \mathrm{CI}=49.0-49.8 \%)$. The population subgroups varied with respect to hypertension prevalence (range: 32.6-73.4\%), awareness (range: 35.1-76.2\%), treatment (range: 24.9-64.6\%), control (range: 3.920.4\%), and control under treatment (range: 11.2-31.6\%).

Hypertension was categorized as unaware of disease, aware but not treated, treated but not controlled, or controlled (Fig. 3). In this study population, hypertension patients accounted for $55.7 \%$, of which $26.3 \%$ were 


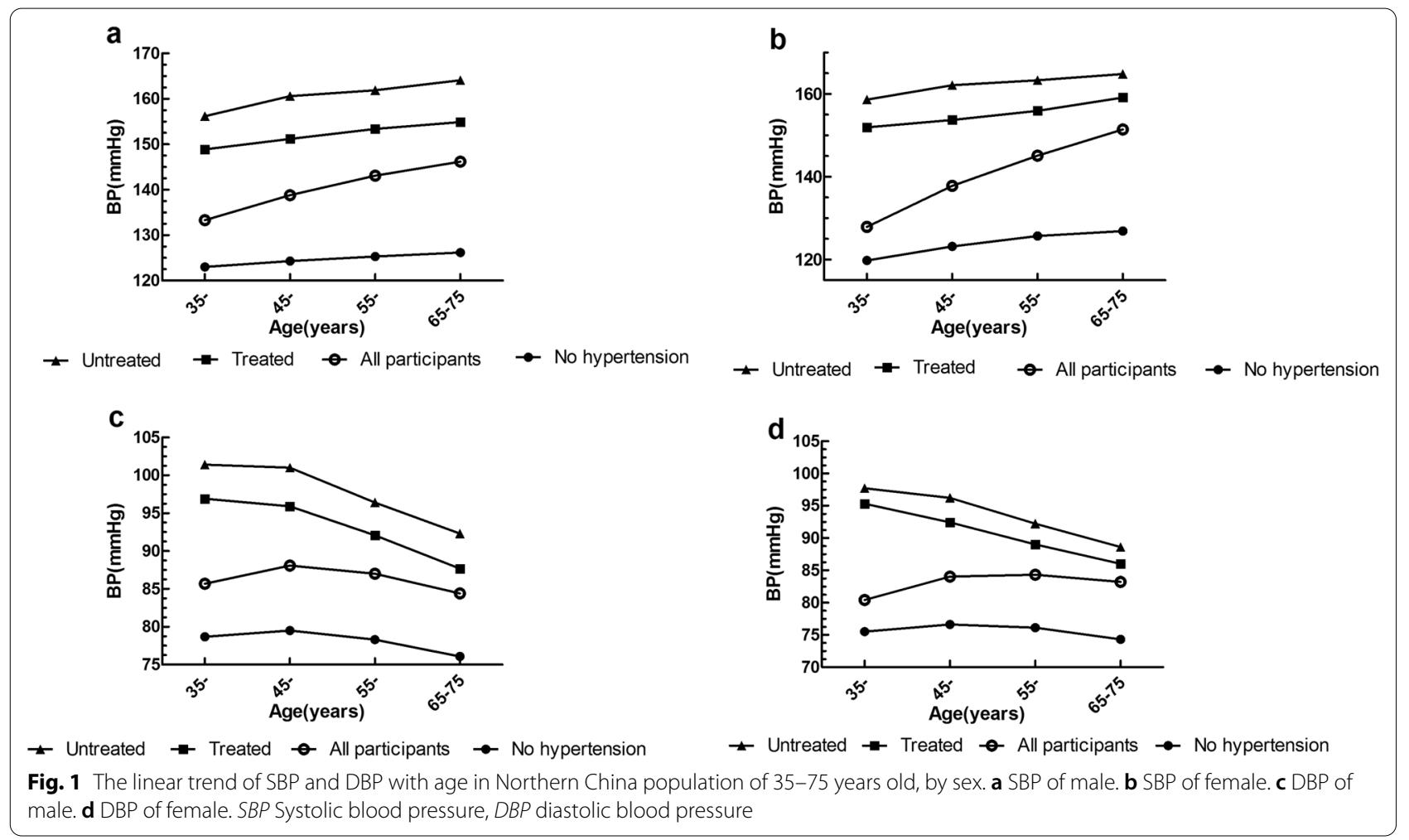

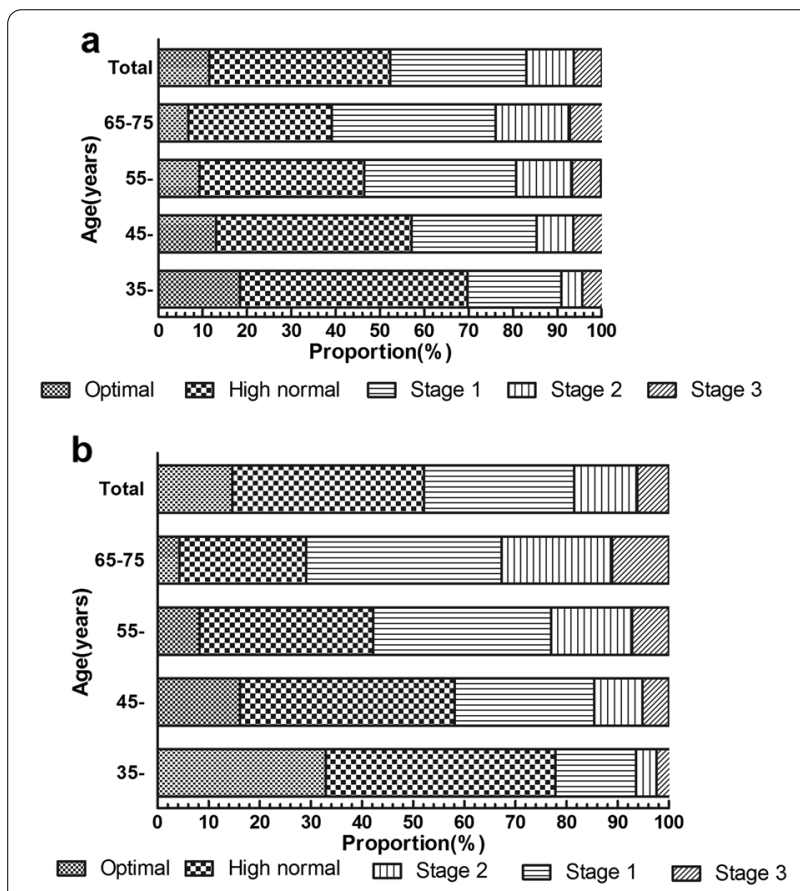

Fig. 2 Percentage distribution of blood pressure levels in Northern China population of 35-75 years old, by sex and age. a Male. $\mathbf{b}$ Female unaware of disease, $19.3 \%$ were treated but not controlled, 5.3\% were aware but not treated, and only $4.8 \%$ were controlled. The proportion of the hypertension patients and the proportion of each part increased with age. The control rate among patients with hypertension was very low among all age groups in both male and female.

\section{The factors associated with prevalence and control of hypertension}

Using the multivariable logistic model, we identified significant determinants that were associated with the prevalence and control of hypertension (Fig. 4). Among all participants who had dyslipidemia, diabetes, obesity, Han, not married, lower educational level, lower annual income, current drinker, non-current smoker, living in rural areas, male and older were significantly more likely to be suffered from hypertension $(P<0.05)$. Patients who were farmer, Mongol, not married, current drinker, non-current smoker, younger, lower educational level, without obesity, without diabetes, without prior $C H D$, and without prior CVD were less likely to be controlled for hypertension $(P<0.05)$.

The odds of hypertension were 5.809 times more in participants of age group 65-75 than those in $35-44$ age group $(\mathrm{ORs}=5.809, \quad 95 \% \mathrm{CI}=5.461-$ $6.179, P<0.001)$. The odds of hypertension in the 
Mongol were 0.835 times that of the Han $(\mathrm{ORs}=0.835$, $95 \% \mathrm{CI}=0.743-0.939, P=0.003)$. Furthermore, hypertension was associated with dyslipidemia $(\mathrm{ORs}=1.351$, $95 \% \mathrm{CI}=1.307-1.397, P<0.001)$; diabetes $(\mathrm{ORs}=1.725$, $95 \% \mathrm{CI}=1.654-1.800, \quad P<0.001) ; \quad$ current drinker $(\mathrm{ORs}=1.297, \quad 95 \% \mathrm{CI}=1.243-1.353, \quad P<0.001)$, and, obesity $(\mathrm{ORs}=2.406,95 \% \mathrm{CI}=2.310-2.506, P<0.001)$. Controlled for hypertension were associated with prior CHD $(\mathrm{ORs}=1.831,95 \% \mathrm{CI}=1.457-2.300, \quad P<0.001)$; older $\quad(65-75 / 35-44: \quad$ ORs $=1.720, \quad 95 \% \mathrm{CI}=1.459-$ $2.029, P<0.001)$; obesity $(\mathrm{ORs}=1.081,95 \% \mathrm{CI}=1.001-$ $1.166, \mathrm{P}=0.047)$; and current drinker $(\mathrm{ORs}=0.792$, $95 \% \mathrm{CI}=0.765-0.820, P<0.001)$.

\section{Discussion}

To the best of our knowledge, this study presents the latest reliable information about the epidemiological situation of hypertension in Inner Mongolia, the largest province in northern China. In the first and largest population survey in Inner Mongolia, we precisely estimated the disease burden of hypertension in Inner Mongolia. In northern China, Inner Mongolia, the rates of prevalence, awareness, treatment, control, and control under treatment for hypertension was $55.7 \%$, $52.8 \%, 43.3 \%, 8.6 \%$, and $19.8 \%$, respectively.

The mean SBP/DBP in our study was 140.5/84.8 mmHg (male 140.7/86.7 $\mathrm{mmHg}$ and female $140.4 / 83.4 \mathrm{mmHg}$ ). Compared to our results, one study conducted in Jilin Province [13], which is located in northern China and had a similar economic level to Inner Mongolia, showed lower blood pressure levels $(130.5 / 85.0 \mathrm{mmHg}$ in males, $128.3 / 81.7 \mathrm{mmHg}$ in females). The results showed that populations had higher blood pressure in Inner Mongolia, especially SBP. There was a closely causal relationship between blood pressure and the incidence and death of cardiovascular and cerebrovascular diseases. The SBP of Asians increased by $10 \mathrm{mmHg}$, and the risk of stroke and myocardial infarction increased by $53 \%$ and $31 \%$, respectively [18]. If we didn't take action, the disease burden caused by hypertension would be serious, in northern China.

We found that hypertension with high prevalence and low control in northern China, which was similar to the results of other previous studies from in Inner Mongolia and northern China [11, 19-22]. The age- and sexstandardized rates of hypertension prevalence were higher than those in a 2017 report from the national report (49.4\% vs. $37.2 \%)$ [6]. Although the prevalence of hypertension has already exceeded that in high-income countries, such as Australia, Canada, and South Korea, the awareness, treatment, and control rates in northern China were far inferior to those in the aforementioned countries $[23,24]$. Even a study conducted in 44 lowincome and middle-income countries showed that the lowest control rate of hypertension was $11.3 \%$ in Belize [25], which was higher than our study results (8.6\%). In addition, most of the hypertension patients in the study were unaware, and were treated but not controlled. Therefore, it is necessary to improve the discipline level and service capabilities of the grassroots units in Inner Mongolia by standardizing the screening for hypertension and comprehensive treatment and implementing comprehensive management and control strategies. In Inner Mongolia, primary health services are in a state of higher demand for health services, but the utilization and resource allocation of primary health services are at a lower level than the whole country [26]. Moreover, the system of tiered diagnosis and treatment for hypertension has not been developed in Inner Mongolia, which could contribute to the standardized management of hypertension and enhance the efficiency of utilization of primary health resources. Therefore, the investment in the resources of the primary health service system and the utilization rate of services in the study region should be improved.

The higher prevalence of hypertension was found in our study may be explained by obesity and a high-salt diet, which were the main modifiable factors associated with hypertension. As well known, a high-salt diet is common in Inner Mongolia. A survey in Inner Mongolia showed that the salt intake was twice more than the recommended salt intake by World Health Organization (WHO) [27]. The Global BMI Mortality Collaboration reported that overweight and obesity significantly increased the risk of all-cause death in the global population [28], and were important risk factors for hypertension $[4,13,29]$ The obesity rate in this study was $24.9 \%$, while the national study in the same period reported that the obesity rate of the 35-75 years old population was $15.7 \%$ [6]. We found the obesity was associated with better hypertension awareness, treatment, and control among hypertensive patients. These findings are in agreement with He's reports [30]. It has been suggested that obesity positively influences hypertension checking and prescription of medication for intervention, hence, higher awareness, treatment and control levels.

People who were older, male, Han, not married, living in rural areas, those with lower education, lower annual income, current drinker, non-current smoker, and coexisting conditions (diabetes, obesity, or dyslipidemia) were more likely to have a higher risk of hypertension. Among people with hypertension, those who were older, Han, not farmer, not married, current smoker, noncurrent drinker, those with higher education, with prior $\mathrm{CHD}$, prior CVD, and coexisting conditions (diabetes 
Table 3 Prevalence, awareness, treatment, control, and control under treatment of hypertension among different groups, \% (95\%Cl)

\begin{tabular}{|c|c|c|c|c|c|}
\hline Groups & Prevalence & Awareness & Treatment & Control & Control under treatment \\
\hline Crude rates & $55.7(55.3-56.1)$ & $52.8(52.3-53.3)$ & $43.3(42.8-43.8)$ & $8.6(8.3-8.9)$ & $19.8(19.2-20.4)$ \\
\hline \multicolumn{6}{|l|}{ Sex } \\
\hline Male & $57.4(56.8-58.0)$ & $49.7(48.9-50.4)$ & $39.6(38.9-40.3)$ & $8.2(7.8-8.6)$ & $20.8(19.8-21.7)$ \\
\hline Female & $54.5(54.0-54.9)$ & $55.2(54.5-55.8)$ & $46.1(45.4-46.7)$ & $8.8(8.5-9.2)$ & $19.2(18.4-20.0)$ \\
\hline \multicolumn{6}{|l|}{ Ethnicity } \\
\hline Han & $56.0(55.6-56.4)$ & $53.6(53.1-54.1)$ & $44.2(43.7-44.7)$ & $8.9(8.6-9.2)$ & $20.2(19.6-20.8)$ \\
\hline Mongol & $52.7(51.4-53.9)$ & $44.6(42.9-46.4)$ & $34.2(32.6-35.9)$ & $5.1(4.4-5.9)$ & $15.0(12.9-17.2)$ \\
\hline Others & $53.2(50.3-56.1)$ & $48.9(44.9-52.9)$ & $38.9(35.0-42.8)$ & $6.0(4.1-7.9)$ & $15.5(10.9-20.2)$ \\
\hline \multicolumn{6}{|l|}{ Age (years) } \\
\hline $35-44$ & $32.6(31.7-33.4)$ & $35.1(33.6-36.6)$ & $24.9(23.5-26.2)$ & $5.3(4.6-6.0)$ & $21.4(18.8-24.0)$ \\
\hline $45-54$ & $50.6(50.0-51.3)$ & $47.9(47.1-48.8)$ & $38.1(37.2-38.9)$ & $8.0(7.5-8.5)$ & $21.0(19.8-22.2)$ \\
\hline $55-64$ & $64.2(63.6-64.8)$ & $56.9(56.1-57.7)$ & $47.8(47.0-48.5)$ & $9.5(9.0-9.9)$ & $19.8(18.9-20.7)$ \\
\hline $65-75$ & $73.4(72.5-74.2)$ & $60.9(59.9-62.0)$ & $51.6(50.5-52.7)$ & $9.3(8.7-9.9)$ & $18.0(16.9-19.2)$ \\
\hline \multicolumn{6}{|l|}{ Marital status } \\
\hline Married & $55.1(54.7-55.5)$ & $53.0(52.5-53.5)$ & $43.4(42.9-44.0)$ & $8.9(8.6-9.2)$ & $20.4(19.8-21.0)$ \\
\hline Not married & $62.0(60.8-63.2)$ & $50.9(49.3-52.5)$ & $41.8(40.3-43.4)$ & $5.9(5.2-6.7)$ & $14.2(12.5-15.9)$ \\
\hline \multicolumn{6}{|l|}{ Farmer } \\
\hline Yes & $56.7(56.2-57.3)$ & $51.8(51.1-52.5)$ & $41.4(40.7-42.1)$ & $7.6(7.2-8.0)$ & $18.4(17.5-19.3)$ \\
\hline No & $54.8(54.2-55.3)$ & $53.8(53.1-54.4)$ & $45.1(44.4-45.7)$ & $9.5(9.1-9.9)$ & $21.0(20.2-21.8)$ \\
\hline \multicolumn{6}{|l|}{ Location of residence } \\
\hline Rural & $56.0(55.6-56.5)$ & $52.5(51.9-53.1)$ & $42.4(41.8-43.0)$ & $8.3(8.0-8.6)$ & $19.5(18.8-20.3)$ \\
\hline Urban & $54.9(54.3-55.6)$ & $53.6(52.7-54.5)$ & $45.3(44.4-46.2)$ & $9.2(8.7-9.8)$ & $20.4(19.3-21.5)$ \\
\hline \multicolumn{6}{|l|}{ Educational level } \\
\hline Primary school or lower & $58.8(58.3-59.5)$ & $54.3(53.6-55.1)$ & $44.3(43.6-45.1)$ & $8.0(7.6-8.4)$ & $18.1(17.2-19.0)$ \\
\hline Middle school & $54.4(53.8-54.9)$ & $53.2(52.4-53.9)$ & $44.0(43.2-44.7)$ & $9.5(9.0-9.9)$ & $21.5(20.6-22.4)$ \\
\hline High school or above & $47.8(46.7-48.9)$ & $49.8(48.2-51.4)$ & $40.1(38.5-41.7)$ & $9.5(8.5-10.4)$ & $23.6(21.5-25.8)$ \\
\hline \multicolumn{6}{|l|}{ Annual income (RMB) } \\
\hline$<10,000$ & $58.6(58.0-59.3)$ & $53.7(52.8-54.6)$ & $42.8(41.9-43.7)$ & $8.2(7.7-8.7)$ & $19.1(18.0-20.2)$ \\
\hline $10,000-50,000$ & $54.4(53.9-54.9)$ & $52.9(52.2-53.6)$ & $44.2(43.5-44.9)$ & $9.0(8.6-9.4)$ & $20.3(19.5-21.1)$ \\
\hline$>50,000$ & $54.2(53.1-55.3)$ & $53.8(52.3-55.3)$ & $43.4(41.9-44.9)$ & $9.2(8.4-10.1)$ & $21.3(19.4-23.1)$ \\
\hline \multicolumn{6}{|l|}{ Health insurance } \\
\hline Yes & $55.5(55.1-55.9)$ & $53.4(52.9-53.9)$ & $43.8(43.3-44.3)$ & $8.8(8.5-9.1)$ & $20.0(19.3-20.6)$ \\
\hline No & $56.9(55.9-57.9)$ & $49.0(47.7-50.4)$ & $39.9(38.6-41.3)$ & $7.4(6.7-8.1)$ & $18.6(17.0-20.3)$ \\
\hline \multicolumn{6}{|l|}{ Diabetes } \\
\hline Yes & $70.2(69.4-70.9)$ & $60.2(59.2-61.2)$ & $50.8(49.8-51.8)$ & $9.6(9.1-10.2)$ & $19.0(17.9-20.1)$ \\
\hline No & $52.2(51.8-52.6)$ & $50.4(49.8-51.0)$ & $40.8(40.3-41.4)$ & $8.2(7.9-8.5)$ & $20.1(19.4-20.9)$ \\
\hline \multicolumn{6}{|l|}{ Obesity } \\
\hline Yes & $71.4(70.7-72.0)$ & $60.7(59.8-61.5)$ & $51.2(50.3-52.1)$ & $8.9(8.4-9.4)$ & $17.4(16.5-18.4)$ \\
\hline No & $50.5(50.1-50.9)$ & $49.1(48.5-49.7)$ & $39.6(39.0-40.2)$ & $8.4(8.1-8.7)$ & $21.2(20.5-22.0)$ \\
\hline \multicolumn{6}{|l|}{ Dyslipidemia } \\
\hline Yes & $62.6(62.0-63.2)$ & $55.6(54.8-56.3)$ & $46.2(45.5-47.0)$ & $8.9(8.4-9.3)$ & $19.2(18.2-20.2)$ \\
\hline No & $51.3(50.8-51.8)$ & $50.7(50.0-51.3)$ & $41.0(40.4-41.7)$ & $8.3(8.0-8.7)$ & $20.3(19.4-21.3)$ \\
\hline \multicolumn{6}{|l|}{ Current smoker } \\
\hline Yes & $53.2(52.5-54.0)$ & $50.7(49.7-51.7)$ & $40.8(39.8-41.8)$ & $9.4(8.8-10.0)$ & $23.0(21.7-24.3)$ \\
\hline No & $56.6(56.1-56.9)$ & $53.5(52.9-54.0)$ & $44.1(43.5-44.6)$ & $8.3(8.0-8.6)$ & $18.9(18.2-19.5)$ \\
\hline \multicolumn{6}{|l|}{ Current drinker } \\
\hline Yes & $57.0(56.3-57.7)$ & $46.4(45.5-47.4)$ & $34.9(34.0-35.8)$ & $6.3(5.9-6.8)$ & $16.0(14.8-17.1)$ \\
\hline No & $55.2(54.8-55.6)$ & $55.3(54.7-55.8)$ & $46.5(45.9-47.1)$ & $9.4(9.1-9.8)$ & $20.3(19.6-21.0)$ \\
\hline
\end{tabular}


Table 3 (continued)

\begin{tabular}{llllcl}
\hline Groups & Prevalence & Awareness & Treatment & Control & Control under treatment \\
\hline $\begin{array}{l}\text { Prior CVD } \\
\text { Yes }\end{array}$ & $72.7(71.2-74.2)$ & $72.0(70.2-73.7)$ & $60.2(58.2-62.1)$ & $14.5(13.1-15.9)$ & $24.1(21.9-26.3)$ \\
$\quad$ No & $54.8(54.4-55.2)$ & $51.5(51.0-52.0)$ & $51.5(51.0-52.0)$ & $8.2(7.9-8.5)$ & $19.4(18.8-20.0)$ \\
Prior CHD & & & & \\
Yes & $68.4(65.8-71.0)$ & $76.2(73.3-79.1)$ & $64.6(61.3-67.8)$ & $20.4(17.7-23.1)$ & $31.6(27.7-35.5)$ \\
sNo & $55.5(55.1-55.8)$ & $52.3(51.8-52.8)$ & $42.8(42.3-43.3)$ & $8.3(8.0-8.6)$ & $19.4(18.8-20.0)$ \\
\hline
\end{tabular}

The value is presented in percent $(95 \% \mathrm{CI})$. CVD Cardiovascular disease, $C H D$ coronary heart disease

or obesity) were more likely to be controlled for hypertension. Although participants of the 35-44 age group had the lowest prevalence of hypertension in our study, their prevalence was higher than the national prevalence of hypertension (32.6\% vs. 22\%) [6], and the 35-44 age group constituted the largest proportion of populations with high normal blood pressure. If the blood pressure of these populations was not well controlled, it will further increase the burden of hypertension. Notably, younger patients had lower awareness, treatment and control rate of hypertension, but had higher control under treatment rate of hypertension. Compared with older adult patients,

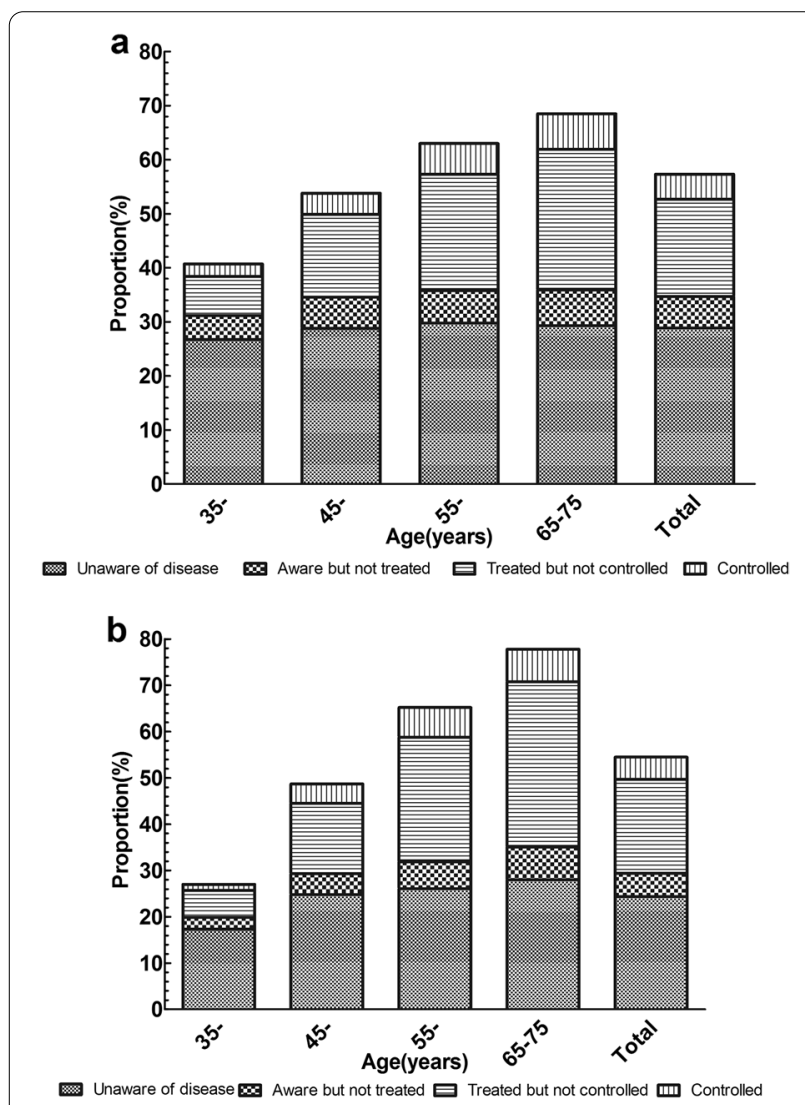

Fig. 3 Awareness and control of hypertension among groups by sex and age. a Male. b Female younger patients lack health awareness, have fewer consultations with clinicians, have more bad habits, are less likely to adhere to prescribed medications, but they have lower blood pressure levels. If younger patients can adhere to regular medication, hypertension can be well controlled. Moreover, most guidelines advocate screening for hypertension from a relatively young age [31]. However, in our study, the participants of the 35-44 age group had the lowest hypertension awareness rate. Thus, screening strategies need to be designed to appeal to individuals of young age.

Because Mongol was the main minority ethnic group in Inner Mongolia, the ethnicity of participants was categorized into three groups including Han Chinese, Mongol, and other minority ethnic groups. Logistic regression analysis showed that the odds of hypertension in the Mongol were 0.835 times that of the Han (ORs $=0.835$, $95 \% \mathrm{CI}=0.743-0.939, P=0.003)$. However, researches by $\mathrm{Li}$ et al. $[13,19,29]$ showed that Mongol populations have a higher prevalence of hypertension than Han populations. Different ethnic-specific genetic susceptibility, environmental exposures and the interactions between gene and environment may account for the different prevalence of hypertension [32]. A study conducted in Inner Mongolia showed that rs 13306673 is a genetic factor for hypertension in the Han population but not in Mongolian population [33]. A further study between hypertension and ethnic specific genetic susceptibility is urgently needed to clarify the observation.

Current drinkers had a higher risk of hypertension prevalence, but worse control. The results of research on the relationship between smoking, drinking and hypertension are inconsistent [34-36]. Some studies showed that smoking had no clear relationship with hypertension. Many studies had shown that hypertension was related to the level of alcohol consumption [35]. However, our study demonstrated that current smoker was a protective factor for hypertension. This can be attributed to the fact that cross-sectional studies cannot determine the sequence of cause and effect and that more hypertension tends to change bad lifestyles, such as quitting smoking. We also observed that people with 


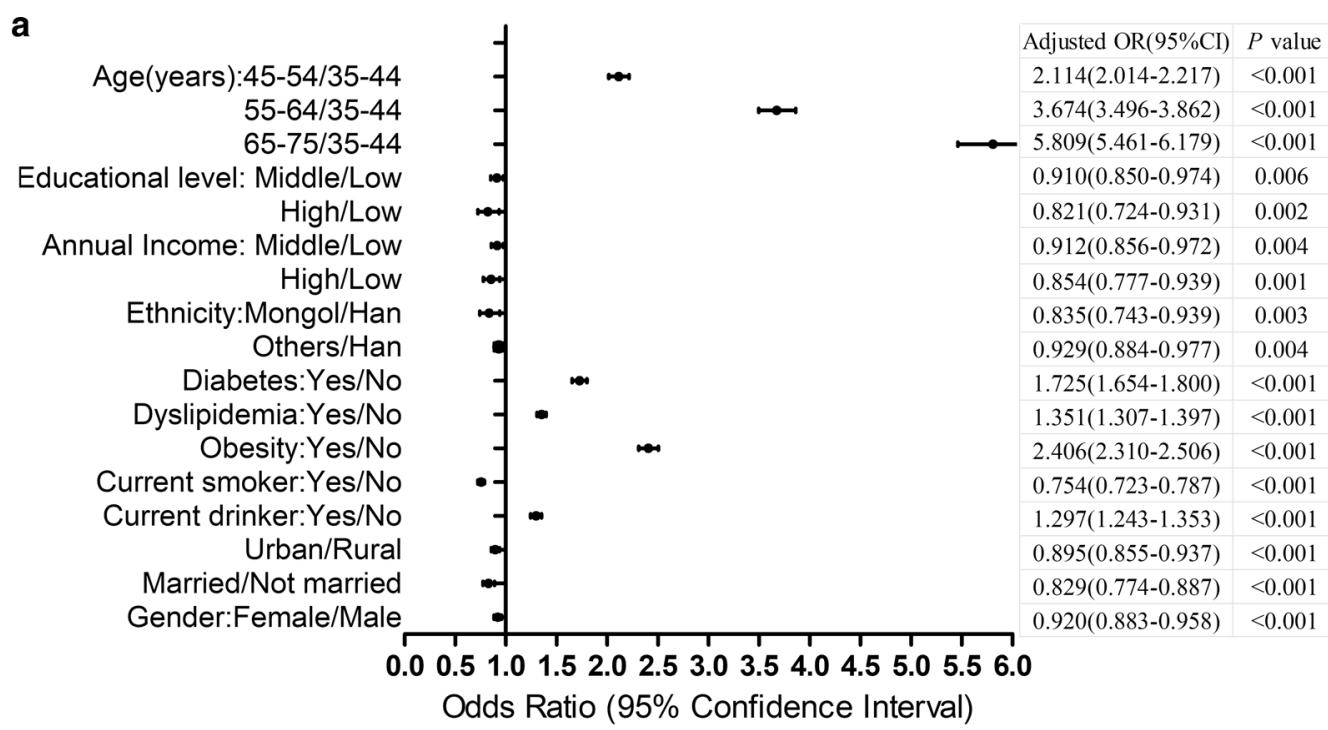

b

Age(years): $45-54 / 35-44$
$55-64 / 35-44$
$65-75 / 35-44$

Educational level: Middle/Low

High/Low

Ethnicity:Mongol/Han

Others/Han

Diabetes:Yes/No

Obesity:Yes/No

Current smoker:Yes/No

Current drinker:Yes/No

Married/Not married

Farmer:Yes/No

CHD:Yes/No

CVD:Yes/No

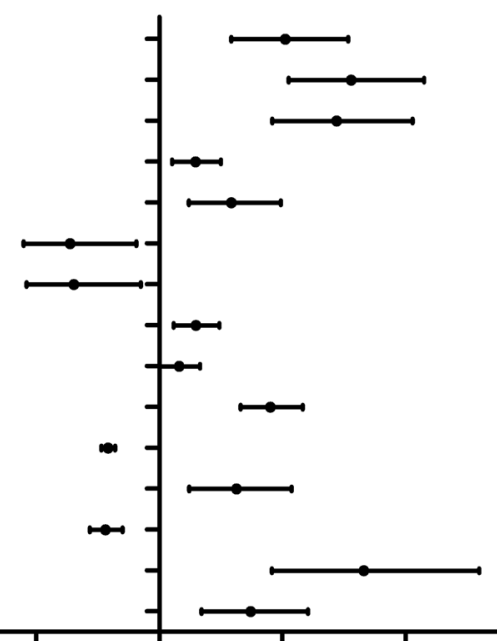

$\begin{array}{lll}1.5 & 2.0 & 2.5\end{array}$

Adjusted OR(95\%CI) $P$ value

$1.511(1.293-1.767)<0.001$

$1.780(1.526-2.076)<0.001$

$1.720(1.459-2.029)<0.001$

$1.147(1.052-1.250) \quad 0.002$

$1.293(1.120-1.493)<0.001$

$0.637(0.448-0.906) \quad 0.012$

$0.652(0.460-0.925) \quad 0.016$

$1.148(1.058-1.244) \quad 0.001$

1.081(1.001-1.166) $\quad 0.047$

$1.451(1.330-1.583)<0.001$

$0.792(0.765-0.820)<0.001$

$1.313(1.121-1.537) \quad 0.001$

$0.781(0.717-0.850)<0.001$

$1.831(1.457-2.300)<0.001$ $1.371(1.172-1.604)<0.001$

Odds Ratio (95\% Confidence Interval)

- Odds Ratio $\longmapsto$ 95\% Confidence Interval

Fig. 4 Multivariable logistic regression showing factors associated with prevalence and control of hypertension in Northern China population. a Prevalence. $\mathbf{b}$ Control

higher educational levels had comparatively lower prevalence and higher control rates. The phenomenon may be because that higher educational level may have a positive impact on the knowledge of hypertension prevention and control, as well as accessibility and adherence to medical treatment [37].

Several studies have found that the risk of hypertension is much higher among males than females, which was consistent with our research results [38, 39]. Compared to females, males are less concerned about the health and have more bad habits [40]. Moreover, we found a rural-urban disparity in the prevalence of hypertension. Compared with urban areas, hypertension with higher prevalence and lower awareness, treatment, and control in rural areas. This suggests that patients with hypertension in rural areas groups should be given more attention in promoting awareness, treatment and improving the management of hypertension. 


\section{Conclusion}

The results of our study suggested that hypertension in northern China is a serious problem, especially a lack of control. Even treated patients with hypertension had still not achieved adequate levels of control. The study supports broad-based opportunities to mitigate the burden of hypertension. We urgently need to develop strategies that focused on controlling the modifiable risk factors, aiming to improve the prevention and control of hypertension.

\section{Limitations}

Because this study was a cross-sectional study, the finding cannot be used to establish a conclusive cause-and-effect relationship between risk factors and hypertension. There are some limitations. First, blood pressure value was measured in a single visit, so its value, as well as the prevalence of hypertension based partly on the measured blood pressure, may have been overestimated. Second, the study did not use representative sampling because it was not possible with such rapid, large-scale recruitment. Based on data from the total population in Inner Mongolia, we adjusted for the main asymmetrical characteristics of the study population, including age, sex, location of residence, and ethnic groups. The adjusted prevalence, awareness, treatment, and control rates of hypertension are very close to the crude rate. Third, we would expect that the rates of prevalence, awareness, treatment, and control were overestimated in our study due to the sampling bias, since the potential participants who were more concerned about their health were more inclined to respond to our study. In addition, because information about diet and exercise was unavailable in our study, the rate of treatment of hypertension could be underestimated, but the control rate would remain unaffected. Lastly, the members in a family who satisfied the inclusion criteria were selected as our study participants; as a result, the correlation of influencing factors within families may have affected the association estimation between influencing factors and hypertension.

\section{Abbreviations \\ SBP: Systolic blood pressure; DBP: Diastolic blood pressure; CVD: Cardiovascu- lar disease; CHD: Coronary heart disease; BMI: Body mass index; SD: Standard deviation; 95\% Cl: 95\% Confidence interval.}

\section{Acknowledgements}

We thank Yunfeng Xi, Liying Qiao, Ke Han ang Gai Hang of Inner Mongolia Centre for Disease Control and Prevention for their support.

\section{Authors' contributions}

$X X$ and $H B$ contributed the central idea. $X X$ wrote the initial draft of the paper. $X X, H B, H Z$ and $L N$ analysed the data. The remaining authors contributed to refining the ideas, carrying out additional analyses and finalizing this paper. All authors gave final approval, and agreed to be accountable for all aspects of work ensuring integrity and accuracy (XX, HB, ZT, HZ, LZ, LN, TY, HD, XF, XZ). All authors read and approved the final manuscript.

\section{Funding}

The author(s) disclosed receipt of the following financial support for the research, authorship, or publication of this article: This work was supported by the Natural Science Foundation Program of Inner Mongolia Autonomous Region (Grant No. 2020MS08048); the National Natural Science Foundation of China (Grant No. 82160639); the Inner Mongolia Medical University ShanXue project of ZhiYuan Talent Plan (Grant No. ZY0201025); the Inner Mongolia Medical University Doctoral Start-up fund project (Grant No. YKD2020BSJJ016); and the Ministry of Finance of China and National Health and Family Planning Commission of China.

\section{Availability of data and materials}

The data that support the findings of this study are available from Early Screening and Comprehensive Intervention Project for High Risk Groups of Cardiovascular Diseases of National Center for Cardiovascular Diseases, but restrictions apply to the availability of these data, which were used under license for the current study, and so are not publicly available. Data are however available from the authors upon reasonable request and with permission of National Center for Cardiovascular Diseases.

\section{Declarations}

Ethics approval and consent to participate

This project was approved by the ethics committee of Fuwai Hospital Chinese Academy of Medical Sciences (approval number: 2014-574). All participants gave their written informed consent.

\section{Consent to publication}

Written informed consent for publication was obtained from all participants.

\section{Competing interests}

The authors declare that there is no conflict of interest.

\section{Author details}

${ }^{1}$ School of Public Health, Inner Mongolia Medical University, Hohhot, Inner Mongolia, People's Republic of China. ${ }^{2}$ Department of Nephrology, Inner Mongolia People's Hospital, Hohhot, Inner Mongolia, People's Republic of China.

${ }^{3}$ Department of Clinical Laboratory, Hohhot First Hospital, Hohhot, Inner Mongolia, People's Republic of China.

Received: 27 June 2020 Accepted: 19 October 2021

Published online: 04 November 2021

\section{References}

1. Forouzanfar $M H$, Afshin A, Alexander LT, et al. Global, regional, and national comparative risk assessment of 79 behavioural, environmental and occupational, and metabolic risks or clusters of risks, 1990-2015: a systematic analysis for the Global Burden of Disease Study 2015. The Lancet. 2016;388:1659-724.

2. Gakidou E, Afshin A, Abajobir AA, et al. Global, regional, and national comparative risk assessment of 84 behavioural, environmental and occupational, and metabolic risks or clusters of risks, 1990-2016: a systematic analysis for the Global Burden of Disease Study 2016. The Lancet. 2017;390:1345-422.

3. Lim SS, Vos T, Flaxman AD, et al. A comparative risk assessment of burden of disease and injury attributable to 67 risk factors and risk factor clusters in 21 regions, 1990-2010: a systematic analysis for the Global Burden of Disease Study 2010. The Lancet. 2012;380:2224-60. 
4. Yin R, Yao L, Chen Y, et al. Prevalence, awareness, treatment, control and risk factors of hypertension in the Guangxi Hei Yi Zhuang and Han populations. Hypertens Res. 2006;29(6):423-32.

5. GBD 2019 Risk Factors Collaborators. Global burden of 87 risk factors in 204 countries and territories, 1990-2019: a systematic analysis for the Global Burden of Disease Study 2019. The Lancet 2020; 396(10258): 1223-1249.

6. Lu J, Lu Y, Wang $X$, et al. Prevalence, awareness, treatment, and control of hypertension in China: data from 1.7 million adults in a populationbased screening study (China PEACE Million Persons Project). The Lancet. 2017;390:2549-58.

7. Li D, LV J, Liu F, et al. Hypertension burden and control in mainland China: analysis of nationwide data 2003-2012. Int J Cardiol. 2015;184:637-44.

8. Li W, Gu H, Teo KK, et al. Hypertension prevalence, awareness, treatment, and control in 115 rural and urban communities involving 47000 people from China. J Hypertens. 2016;34:39-46.

9. Zhang J, Zheng Y, Guo Z, et al. The diversity of intestinal microbiota of Mongolians living in Inner Mongolia, China. Benef Microbes. 2013;4:319-28.

10. Wu Y, Huxley R, Li L, et al. Prevalence, awareness, treatment, and control of hypertension in China: data from the China National Nutrition and Health Survey 2002. Circulation. 2008;118:2679-86.

11. Wang J, Zhang L, Wang F, et al. Prevalence, awareness, treatment, and control of hypertension in China: results from a national survey. Am J Hypertens. 2014;27:1355-61.

12. Wei Q, Sun J, Huang J, et al. Prevalence of hypertension and associated risk factors in Dehui City of Jilin Province in China. J Hum Hypertens. 2015;29(1):64-8.

13. Du M, Yin S, Wang P, et al. Self-reported hypertension in Northern China: a cross-sectional study of a risk prediction model and age trends. BMC Health Serv Res. 2018;18:475-85.

14. The Revision Committee of the Chinese Guidelines for the Prevention and Treatment of Hypertension. The 2018 revision of the Chinese Guidelines for the Prevention and Treatment of Hypertension. Prevention and Treatment of Cardiovascular and Cerebrovascular Diseases 2019; 19(01):1-44 (in Chinese).

15. Zhou BF. Predictive values of body mass index and waist circumference for risk factors of certain related diseases in Chinese adults - study on optimal cut-off points of body mass index and waist circumference in Chinese adults. BES. 2002;15:83-96.

16. Chinese Diabetes Society. Guidelines for the prevention and control of type 2 diabetes in China (2017 Edition). Chinese Journal of Practical Internal Medicine 2018; 38(4): 292-344 (in Chinese).

17. Zhu J, Gao R, Zhao S, et al. Chinese guideline for the prevention and treatment of dyslipidemia in adults (2016 revision). Chin Circ J. 2016;16:15-35 ((in Chinese)).

18. Lawes CM, Rodgers A, Bennett DA, et al. Blood pressure and cardiovascular disease in the Asia Pacific region. J Hypertens. 2003;21(4):707-71620.

19. Gu H, Li W, Yang J, et al. Hypertension prevalence, awareness, treatment and control among Han and four ethnic minorities (Uygur, Hui, Mongolian and Dai) in China. J Hum Hypertens. 2015;29:555-60.

20. Chen X, Wei W, Zou S, et al. Trends in the prevalence of hypertension in island and coastal areas of china: a systematic review with meta-analysis. Am J Hypertens. 2014;27:1503-10.

21. Liang Y, Liu R, Du S, et al. Trends in incidence of hypertension in Chinese adults, 1991-2009: the China Health and Nutrition Survey. Int J Cardiol. 2014;175:96-101.

22. Boo S, Yoon YJ, Oh H. Evaluating the prevalence, awareness, and control of hypertension, diabetes, and dyslipidemia in Korea using the NHIS-NSC database: A cross-sectional analysis. Medicine (Baltimore) 2018;97:e13713.

23. Zhou B, Danaei G, Stevens GA, et al. Long-term and recent trends in hypertension awareness, treatment, and control in 12 high-income countries: an analysis of 123 nationally representative surveys. The Lancet. 2019;394(10199):639-51.

24. Kang SH, Kim SH, Cho JH, et al. Prevalence, awareness, treatment, and control of hypertension in Korea. Sci Rep. 2019;9:10970-8.

25. Geldsetzer P, Manne-Goehler J, Marcus M-E, et al. The state of hypertension care in 44 low-income and middle-income countries: a crosssectional study of nationally representative individual-level data from 1.1 million adults. The Lancet. 2019:394(10199):652-62.
26. Zhang N, Chen Y, Li M, et al. Comprehensive evaluation of primary health care services in Inner Mongolia autonomous region. J Inner Mongolia Med Univ. 2015;37:299-301 ((in Chinese))

27. Feng $Y$. The study of nutrition and health Statu in some poor regions at east of Inner Mongolia. Inner Mongolia: Inner Mongolia Medical University; 2015. ((in Chinese)).

28. Global BMIMC. Body-mass index and all-cause mortality: individual-participant-data meta-analysis of 239 prospective studies in four continents. The Lancet 2016; 388(10046): 776-86.

29. Li G, Wang H, Wang Ke, et al. Prevalence, awareness, treatment, control and risk factors related to hypertension among urban adults in Inner Mongolia 2014: differences between Mongolian and Han populations. BMC Public Health. 2016;16(1):1-10.

30. He J, Muntner P, Chen J, et al. Factors associated with hypertension control in the general population of the United States. Arch Intern Med. 2002;162:1051-8.

31. Williams B, Poulter NR, Brown MJ, et al. Guidelines for management of hypertension: report of the fourth working party of the British Hypertension Society, 2004-BHS IV. J Hum Hypertens. 2004;18:139-85.

32. Hasi T, Hao L, Yang L, et al. Acetaldehyde dehydrogenase 2 SNP rs671 and susceptibility to essential hypertension in Mongolians: a case control study. Genet Mol Res. 2011;10(1):537-43.

33. Chang PY, Zhao LG, Su XL. Association of TSC gene variants and hypertension in Mongolian and Han populations. Genet Mol Res. 2011;10(2):902-9.

34. Xin X, He J, Frontini MG, et al. Effects of alcohol reduction on blood pressure: a meta-analysis of randomized controlled trials. Hypertension. 2001;38(5):1112-27.

35. Holmes MV, Dale CE, Zuccolo L, et al. Association between alcohol and cardiovascular disease: Mendelian randomisation analysis based on individual participant data. BMJ. 2014;349:94164-4180.

36. Wang S. Cross-sectional study on chronic disease and risk factors among adult residents in Jilin Province. Jilin: Jilin University; 2015. ((in Chinese)).

37. Grotto I, Huerta M, Sharabi Y. Hypertension and socioeconomic status. Curr Opin Cardiol. 2008;23:335-9.

38. Bozza R, Campos W, Barbosa Filho VC, et al. High blood pressure in adolescents of Curitiba: prevalence and associated factors. Arq Bras Cardiol. 2016;106(5):411-8.

39. Khanam MA, Lindeboom W, Razzaque A, et al. Prevalence and determinants of pre-hypertension and hypertension among the adults in rural Bangladesh: findings from a community-based study. BMC Public Health. 2015;15:203-12.

40. Vigna-Taglianti F, Vadrucci S, Faggiano F, et al. Is universal prevention against youths' substance misuse really universal? Gender-specific effects in the EU-Dap school-based prevention trial. J Epidemiol Commun Health. 2009;63:722-8.

\section{Publisher's Note}

Springer Nature remains neutral with regard to jurisdictional claims in published maps and institutional affiliations.

Ready to submit your research? Choose BMC and benefit from:

- fast, convenient online submission

- thorough peer review by experienced researchers in your field

- rapid publication on acceptance

- support for research data, including large and complex data types

- gold Open Access which fosters wider collaboration and increased citations

- maximum visibility for your research: over 100M website views per year

At BMC, research is always in progress.

Learn more biomedcentral.com/submissions 